\title{
Primitive Tumor of the Chest Wall: About 16 Cases and Review of the Literature
}

\author{
Ammor FZ ${ }^{1 *}$, Rabiou $\mathbf{S}^{1}$, Issoufou I', Belliraj L1', Ghalimi $\mathrm{J}^{1}$, Ouadnouni $\mathbf{Y}^{1,2}$ and Smahi $\mathbf{M}^{1,2}$ \\ ${ }^{1}$ Department of Thoracic Surgery, CHU Hassan II of Fes, Morocco \\ ${ }^{2}$ Faculty of Medicine and Pharmacy, University Sidi Mohamed Ben Abdellah, Fes Morocco
}

\section{Introduction}

Chest wall tumors are a heterogeneous group of lesions, they represent less than $5 \%$ of thoracic cancers [1] in 3 forms, which are in order of decreasing frequency: chest metastases, tumors of soft tissue invading the chest by contiguity, and finally, primary tumors of the chest wall (muscle or bone origin) [2]. Wound surgical resection remains an effective way to prevent or treat complications, and improve the quality of life for these patients, sometimes requiring a surgical reconstruction of the defects caused by resection. This work is intended to assess the results of surgical treatment of these tumors through the experience of our service, and set some predictors of morbi-mortality.

\section{Patients and Methods}

This is a retrospective study conducted over a period of 7 years; from February 2009 to December 2015, compiling 16 cases of tumors primitive of the chest wall in the Department of thoracic surgery of CHU Hassan II of Fez, they have received an oncological resection, arriving sometimes at a total parietectomie, with parietal reconstruction, by analyzing postoperative fate and the risk factors of occurrence of postoperative complications immediate or long term.

\section{Results}

It was 11 men and 5 women, the average age was 42 with extremes from 17 to 77 , among the pathological history: a patient treated for pulmonary tuberculosis, a notion of chronic smoking, and three patients had been operated for Dermatofibrosarcoma of Darrier and Ferrand (which two were dual operated at 3 year intervals), and one was operated for a tumor type PNET.

The mean diagnostic delay was 21,52 mois, with extremes ranging from 2 weeks to 11 years, the clinical presentation was in $93 \%$ of cases by a pain associated to a thoracic mass that were in $36 \%$ of cases in lateral side (which $18 \%$ left, $18 \%$ right) and $36 \%$ was anterior and $28 \%$ posterior; in four recurrences, the tumor arise next to the old scar of the surgical incision (Figure 1).

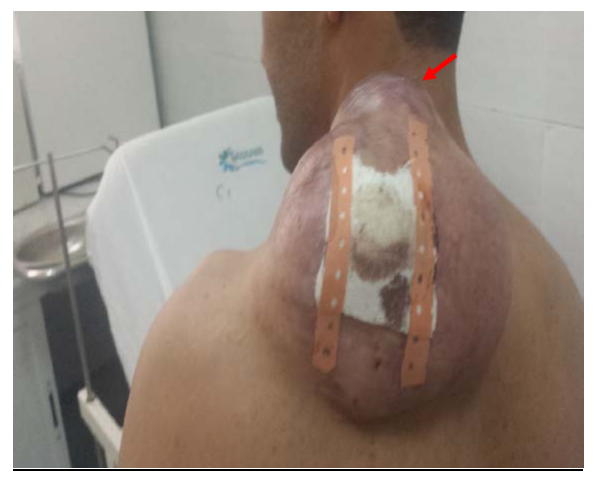

Figure 1: Clinical Presentation of a recurrence of Dermatofibrosarcoma of Darier and Ferrand operatedsince 3 years, by a mass furious on the oldscar sus scapular, early more than $20 \mathrm{~cm}$ tall with presence of Telangiectasia and collateralvenous circulation.
The average tumor size was $7.8 \mathrm{~cm}$ with extremes ranging from 2 to $20 \mathrm{~cm}$. In $25 \%$ of cases the tumor was necrotic and infected, all patients benefited from thoracic CT scan which were able to detect a parietal tissue mass. The assessment of tumor extension (TDM CTAP or MRI) could detect in $20 \%$ an exo-endo-thoracic extension, hitting diaphragm and spinal; and it was negative in $80 \%$ of cases (Figure 2).

The histological diagnosis was established in 6 patients by biopsy, and the 10 other by anatomo-pathological examination of the tumor mass. In our series, it was 10 cases of dermatofibrosarcoma of Darrier and Ferrand grade I; 2 cases of bone tumor (chondrosarcomas, PNET); 2 cases of sarcoma of soft tissue (elastofibrosarcoma, myxofibrosarcoma), 1 case of malignant tumor of the sheath of the peripheral nerves (11th intercostal nerve), 1 case of desmoid disease (Figures $3 a$ and $3 b$ ).

All tumors were treated by a surgical excision with 2 to $5 \mathrm{~cm}$ of safety margins in the periphery. In depth, resections were limited to invaded underlying muscle (pectoralis, small pectorals, latissimus dorsi, sternocleidomastoid, trapeze), requiring in $31 \%$ of case a parietectomies with rib resection, ranging from one to 4 ribs. In 3 cases diaphragmatic resection was done with reattaching at the rib sus underlying. Only $62.5 \%$ who received a parietal reconstruction either by setting up a prosthetic polypropylene plate ( 3 cases), transposition of the latissimus dorsi muscle ( 3 cases), skin transplantation in 4 cases (from the anterior surface of the thigh); ending the gesture by drainage of the tumor bed by a drain of redon associated with pleural drainage in case of rib resection (4 cases) (Figure 4).

Duration of hospitalization was an average of 7 days with

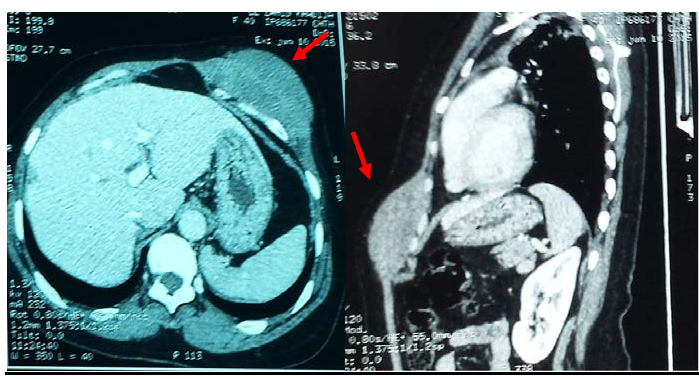

Figure 2: Thoracic CT transversal and sagittal Cupobjectifying a chest tissue massnext to the EIC 10th making $89 / 48 \mathrm{~mm}$ with costal lysis of the $9,10^{\text {th }}$ ribs, and tissue invasion.

*Corresponding author: Ammor FZ, Department of Thoracic Surgery, CHU Hassan II of Fes, Morocco, Tel: 00212652090910; E-mail: dr.a.ammor@gmail.com

Received June 13, 2016; Accepted July 18, 2016; Published July 28, 2016

Citation: Ammor FZ, Rabiou S, Issoufou I, Belliraj L, Ghalimi J, et al. (2016) Primitive Tumor of the Chest Wall: About 16 Cases and Review of the Literature. Med Rep Case Stud 1: 120. doi: 10.4172/2572-5130.1000120

Copyright: @ 2016 Ammor FZ, et al. This is an open-access article distributed under the terms of the Creative Commons Attribution License, which permits unrestricted use, distribution, and reproduction in any medium, provided the original author and source are credited. 


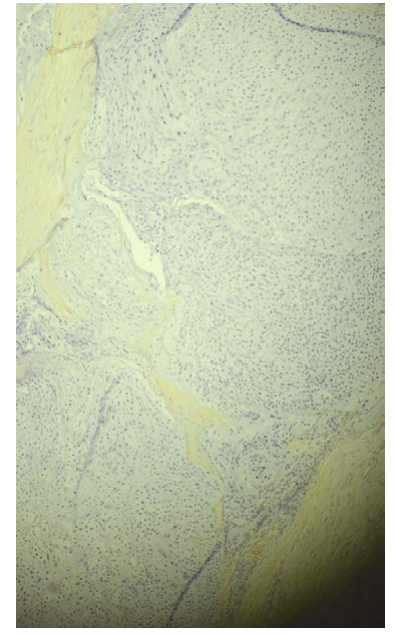

Figure 3a: Chondrosarcoma with lobulated architecture and high celldensity grade II according to classification of O 'Neal and Ackermann, (X 10).

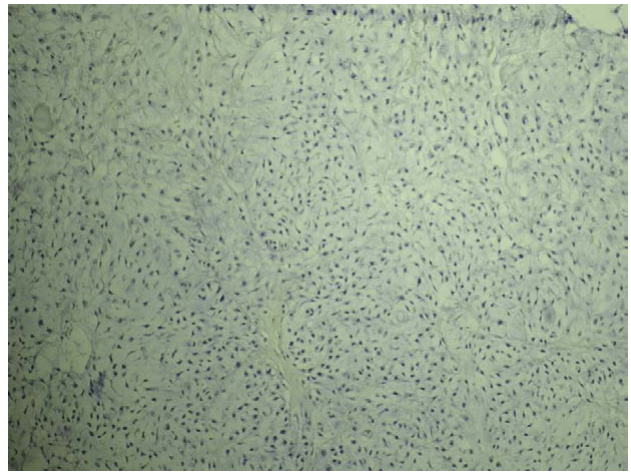

Figure 3b: Tumorcells are provided with hyperchromaticnuclei with numerous images of binucléations (X20). hondrosarcoma grade II as classified by O'Neal and Ackermann.

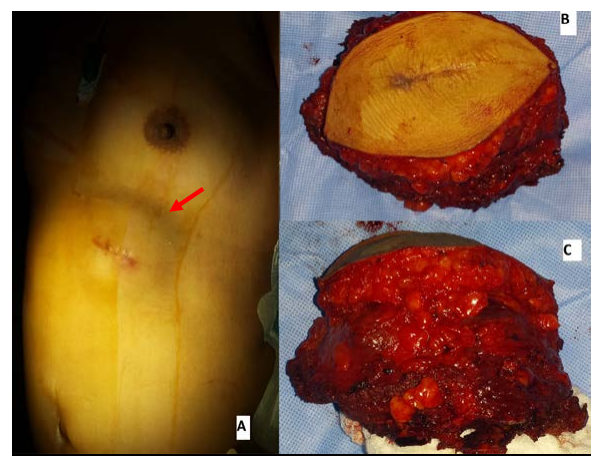

Figure 4: A) Desmoiddisease confirmed by incisionalbiopsy, where the chest CT objectified a parietal mass with costal Lysis $9,10^{\text {th }}$ leftribs with flooding tissue. B,C): wide Resection of the tumor with $4 \mathrm{~cm}$ of lateralre section margin, with parietectomie taking the $9,10^{\text {th }}$ ribs.

extremes, ranging from 3 to 10 days, the longest duration were the parietectomies extended carrying more than 2 ribs. We have noted no immediate postoperative Complications including : bruises or infections or partial or total necrosis because almost all of our patients have beneficied from a preventive postoperative antibiotics for 3 weeks.
The decline was between one to four years, where we have noted only 2 cases which had wound healing disorder, defined by the need for long-term local care with a directed healing in service of reconstructive surgery or Dermatology. Almost $18 \%$ of our patients were referred to the Department of Oncology for adjuvant radio-chemotherapy. We regret no case of death or loss of shreds in our study.

\section{Discussion}

Tumors of the chest wall are a very heterogeneous set of chest diseases, whose main common point is the prospect of a surgical treatment. Wide resection, sometimes involving a parietectomie remains the only treatment increasing the survival of malignant tumours, which represent $27 \%$ of primary tumors of the chest wall [3].

They may be initially asymptomatic, which explains the delay of time diagnostic which was with an average length of 21.52 months in our study. The disease can affect any age confused which was an average of 43 years with extremes of widely variable, on our study, and as reported in the literature, with a male predilection $[4,5]$.

Due to the large variation in the origin of the chest wall tumors, the scanner coupled with MRI remains the gold standard and bestperforming for diagnostic, extensions [6], and preoperative mapping in order to better study the aggressiveness of the tumour and its endo-exo-thoracic extension, for a possible neo adjuvant treatment, and study the extent of resection and explore possibilities for parietal reconstruction [7].

Histological analysis of the tumor remains essential for the development of a correct therapeutic strategy [8], by fine-needle aspiration where Ayala [9] showed 79\% accuracy in the diagnosis of exclusively bone tumours, that's hilights the incisional biopsy with a macro-fragments, this last defines diagnosis in $31 \%$.

Note that chondrosarcomas are the entity most frequent in terms of literature [10-13]. Yet in our study, the dermatofibroscaroma of Darrier and Ferrand ranked first, explained by the default oncological resection, which remains that the recurrence is a prognosis factor, very dependent of the surgical margin $[14,15]$.

Tumor resection should be broad taking the tumor in monobloc $[16,17]$, while respecting the safety margins $(4 \mathrm{~cm}$ for malignant tumours, carrying a sus - and underlying ribs [18,19]; $2 \mathrm{~cm}$ for benign tumors, metastases and tumors of low grades [17]) which must be controlled by pathological examinations in extemporaneous; to minimize the risk of local recurrence and improve survival especially for recurrent tumors (Desmoids tumors, Dermatofibrosarcoma of Darier and Ferrand).

A study at the Mayo Clinic reported a survival at 5 years of $56 \%$ among those with a safety margin of $4 \mathrm{~cm}$ versus $29 \%$ when a margin of $2 \mathrm{~cm}$ or less could be obtained [18], which explains the good results obtained in our study; where there have been no cases of recurrence or death given that all our safety margins met the recommendations.

The reconstruction of the chest wall is the corollary of a large primary resection, which the principles have been reformulated by $\mathrm{Mc}$ Cormack [19]. In general, defects under $5 \mathrm{~cm}$ or less than $7 \mathrm{~mm}$ for the apical and scapular locations, or limited to 2 adjacent sides don't require a reconstruction. A simple approximation of the adjacent ribs is sufficient [19].

On the other hand, the resection of $5 \mathrm{~cm}$ or less, located near the tip of the scapula may justify a reconstruction to avoid the isolation of 
the scapula in the chest wall. All other defects of 5 to $10 \mathrm{~cm}$ must be reconstructed [20-22].

Reconstruction may be biological: by the myocutaneous flaps of the thorax (latissimus dorsi, pectoralis major, large serrated, trapeze) can be mobilized on a rotation axis and transposed elsewhere on the chest wall $[23,24]$ practiced in $20 \%$ in our study where the latissimus dorsi has been transposed with good postoperative evolution associated with a skin plasty. This last is especially practiced in the recovery of the sidewall; Advantageous by its organic nature, its long term stability and resistance to infection [25].

As it can appeal to synthetic materials as : Polyglactin $\left(\right.$ Vicryl $\left.^{\circledR}\right)$ resorbable plates, polydioxanone $\left(\mathrm{PDS}^{\circledR}\right)$, polyethylene tetraphtalate no resorbable plates (Mersilene $\left.{ }^{\star}\right)$, polypropylene (Marlex ${ }^{\star}$ Ouprolene $\left.^{\star}\right)$, plates of expanded polytetrafluoroethylene at $2 \mathrm{~mm}\left(\right.$ Goretex $\left.^{\circ}\right)$ [26], which have also the advantage of quick, easy and stable repair at the outset, used in $18 \%$ of cases of our study, when wide resection of more 2 ribs (Figure 5).

The parietectomie of a primary or metastatic tumor plans to prevent or treat complications such as bleeding, ulceration, metastatic extension and improve the quality of life of these patients [27], that said to prevent all postoperative complications that remain well-known:

At short term, the infection comes to mind observed in $7.4 \%$ in the A.Chapelier series [28], not deplored in our series explained by preventive postoperative antibiotic therapy; followed by the partial or total necrosis are rare in trained teams like Walker et al. [29].

At the longer term, the recurrences come in mind, more frequent during Dermatofibrosarcoma of Darier and Ferrand, reported in $18 \%$ cases in our series and $6 \%$ for bone tumors in type of PNET.

Postoperative morbidity is mainly linked to the surface of chest resection, in order to avoid the large defects, the intervention of a plastic surgeon or dermatologist experience for a directed healing (Figure 6) in $20 \%$ of cases reported in our study. We have no deaths, what remains consistent with the literature as to the series of Aukema, which reported a morbidity rate estimated at $20 \%$, without detected mortality [30,31].

\section{Conclusion}

The parietectomie with parietal reconstruction during chest wall

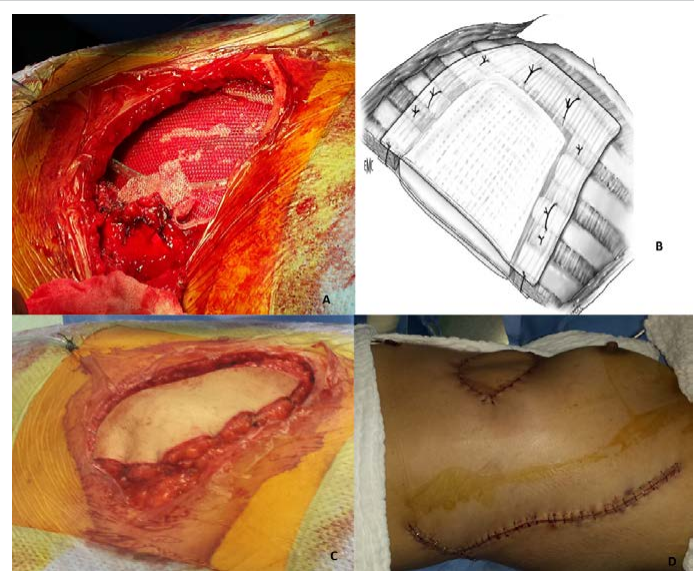

Figure 5: $A, B$ ) Total Parietectomie for a desmoid with establishment of a resorbable plate of polypropylene with an immobilization redon. C,D): transposition of the muscle latismuss dorsal flap.

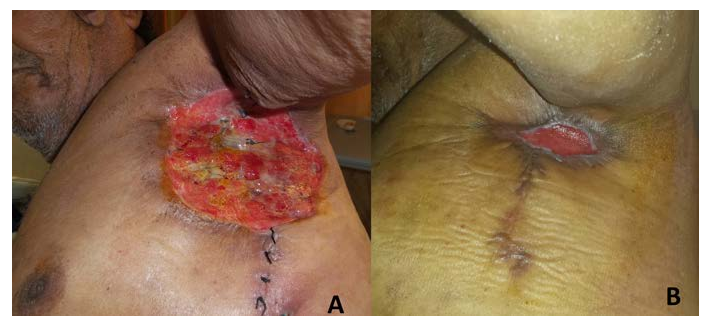

Figure 6: A) Wide resection of axillarytumor with $5 \mathrm{~cm}$ safety margins. B) Results after 7 months of healingled in reconstructive surgery service.

tumors became common, as long as it worsens, in itself, the prognosis. The results in terms of morbidity and mortality have become acceptable. Our study had limits having regard to the heterogeneous group of patients with sarcomas of soft tissue and included bones, as well as the small number of included patients. In addition, there was some significant prognostic factors; such as the surgical resection margins and the extent of resection that depending on diagnostic time and histological type; requiring a careful preoperative evaluation with a multidisciplinary approach for optimal results.

\section{References}

1. David EA, Marshall MB (2011) Review of chest wall tumors: a diagnostic therapeutic, and reconstructive challenge. Seminars in plastic surgery 25: 16-24.

2. Stelzer P, Gay WA (1980) Tumors of the chest wall. Surg Clins North Am 60 : 779-791.

3. Brouchet L, Ballouhey Q, Brouchet A, Giron J, Berjaud J (2010) Tumeurs primitives de la paroi thoracique. Pneumologie.

4. Bagheri R, Haghi SZ, Kalantari MR, Attar AS, Salehi M, et al. (2014) Primary malignant chest wall tumors: analysis of 40 patients. Journal of Cardiothoracic Surgery 9: 106.

5. Maiouak S, Benjelloun H, Zaghba N, Bakhatar A, Yassine N, et al. (2015) Les tumeurs primitives de la paroi thoracique (à propos de 11 cas). Revue des Maladies Respiratoires 32: A121. 4

6. Tateishi U, Gladish GW, Kusumoto M, Hasegawa T, Yokoyama R, et al. (2003) Chest wall tumors: radiologic findings and pathologic correlation: part 1. Benign tumors. Radiographics 23: 1477-1490.

7. Gaillard J, Dahan M (1990) Les tumeurs primitives de la paroi thoracique Éditions Scientifiques et Médicales Elsevier SAS.

8. Incarbone M, Pastorino U (2001) Surgical treatment of chest wall tumors. World J Surg 25: 218-230.

9. Ayala AG, Zornosa J (1983) Primary bone tumors: percutaneous needle biopsie. Radiology 149: 675-679.

10. Burt M, Fulton M, Wessner-Dunlap S, Karpeh M, Huvos AG, et al. (1992) Primary bony and cartilaginous sarcomas of chest wall: results of therapy. Ann Thorac Surg 54: 226-232.

11. Rascoe PA, Reznik SI, Smythe WR (2011) Chondrosarcoma of the thorax Sarcoma: 342879 .

12. Kucharczuk JC (2012) Chest wall sarcomas and induction therapy. Thorac Surg Clin 22: 77-81.

13. Smith SE, Keshavjee S (2010) Primary chest wall tumors. Thorac Surg Clin 20: 495-507.

14. Widhe B, Bauer HC (2009) Surgical treatment is decisive for outcome in chondrosarcoma of the chest wall: a population-based Scandinavian Sarcoma Group study of 106 patients. J Thorac Cardiovasc Surg 137: 610-614.

15. King RM, Pairolero PC, Trastek VF, Piehler JM, Payne WS, et al. (1986) Primary chest wall tumors: factors affecting survival. Ann Thorac Surg 41: 597-601.

16. Cotton BH, Paulsen GA, Dykes J (1956) Prosthesis following excision of ches wall tumors. J Thorac Surg 31: 45-59. 
Citation: Ammor FZ, Rabiou S, Issoufou I, Belliraj L, Ghalimi J, et al. (2016) Primitive Tumor of the Chest Wall: About 16 Cases and Review of the Literature. Med Rep Case Stud 1: 120. doi: 10.4172/2572-5130.1000120

Page 4 of 4

17. Dahan M, Brouchet L, Berjaud J, Garcia O (2003) Chirurgie des tumeurs de la paroi thoracique. Ann Chir Plast Esthet 48: 93-98.

18. Anderson BO, Burt ME (1994) Chest wall neoplasms and their management. Ann Thorac Surg 58: 1774-1781.

19. Mc Cormack PM (1989) Use of prosthetic materials in chest-wall reconstruction. Surg Clin North Am 69: 965-976.

20. Deschamps C, Tirnaksiz BM, Darbandi R, Trastek VF, Allen MS, et al. (1999) Early and long-term results of prosthetic chest wall reconstruction. J Thorac Cardiovasc Surg 117: 588-591.

21. Niwa H, Yamakawa Y, Kobayashi S, Kasugai T, Masaoka A, et al. (1991) Preservation of pulmonary function by chest wall reconstruction. Nippon Geka Gakkai Zasshi 92: 1359-1362.

22. Mansour KA, Thourani VH, Losken A, Reeves JG, Miller JI, et al. (2002) Chest wall resections and reconstruction: a 25-year experience. Ann Thorac Surg 73: $1720-1725$.

23. Larson DL, McMurtrey MJ (1984) Musculo-cutaneous flap reconstruction of chest-wall defects: an experience with 50 patients. Plast Reconstr Surg 73: 734-740.
24. Watson WL, James AG (1947) Fascia lata grafts for the chest wall defects. J Thorac Surg 16: 399-406.

25. Arnold PG, Pairolero PC (1984) Chest wall reconstruction: experience with 100 consecutive patients. Ann Surg 199: 725-732.

26. Arnold PG, Pairolero PC (1996) Chest-wall reconstruction: an account of 500 consecutive patients. Plast Reconstr Surg 98: 804-810.

27. Sankale AA, Diatta $S$ (2013) Reconstruction de la paroi thoracique après pariétectomie majeure: A propos de 6 cas. Ann Afr Thor Cardiovasc 8: 59-63.

28. Chapelier A, Missana MC, Couturaud B (2004) Sternal resection and reconstruction for primary malignant tumors. Ann Thorac Surg 77: 1001-1006.

29. Weyant MJ, Bains MS, Venkatraman E, Downey RJ, Park BJ, et al. (2006) Results of chest wall resection and reconstruction with and without rigid prosthesis. Ann Thorac Surg 81: 279-285.

30. Aukema TS, Russell NS, Wesseling J, Rutgers EJ (2009) Extensive soft tissue resection with autologous tissue closure for locally recurrent breast cancer: Lasting local control and acceptable morbidity. European Journal of Surgical Oncology 35: 469-474.

31. Marcheix B, Brouchet L, Berjaud J, Gomez A, Dahan M (2005) Techniques de réparation de la paroi thoracique. EMC-Chirurgie 2: 252-265. 